\title{
Does the Conservation of Land Reduce Development? An Econometric-Based Landscape Simulation with Land Market Feedbacks
}

\author{
Katherine Y. Zipp ${ }^{1}$, David J. Lewis ${ }^{2}$, and Bill Provencher ${ }^{3}$
}

\begin{abstract}
We use an econometrically-based landscape simulation to investigate the effect of conservation on the net change in local development - the amount of land directly protected from development minus the amount of development that may occur on neighboring unprotected private land in response to conservation. First, we use spatial-panel data from Wisconsin to estimate parcel-level subdivision probabilities and density expectations, controlling for the endogenous location of open space. Second, we use these subdivision probabilities and density expectations in a landscape simulation model. Our simulation results indicate that $57 \%$ of conserved open space created between 1978 and 2009 generated close to zero net change in local development. This suggests that conserved open space mostly reallocated development in a small neighborhood (in a half-mile radius) rather than altering the total amount of development. We explore the landscape conditions that may lead to conservation having either a positive or negative effect on local development.
\end{abstract}

Keywords: land use, open-space conservation, wildlife habitat, micro-econometrics, spatial simulation

\section{Acknowledgements}

We are grateful for the research and GIS assistance provided by Volker Radeloff and Shelley Schmidt, University of Wisconsin - Madison, Department of Forest and Wildlife Ecology. We also thank the Door County Planning Department especially Mariah Goode, Audrey Forslund, Tom Haight, and David Sautebin and the Nature Conservancy especially Mike Grimm. We acknowledge helpful conversations with Volker Radeloff and Steve Polasky about constructing the landscape simulations. We acknowledge comments from seminar participants at the 2011 AERE annual meeting in Seattle, the 2014 Land Use and Ecosystem Services Workshop at UC Santa Barbara, the USDA Economic Research Service, Michigan State University, and Pennsylvania State University. Funding was provided by the National Oceanic and Atmospheric Administration (NOAA) Wisconsin Sea Grant (\#NA06OAR4170011 and \#NA10OAR4170070). We also thank the editor (Roger von Haefen) and two anonymous reviewers for their comments and suggestions.

\footnotetext{
${ }^{1}$ Assistant Professor Department of Agricultural Economics, Sociology, and Education Pennsylvania State University 112-F Armsby University Park, PA 16802 kyz1@psu.edu (corresponding author)

${ }^{2}$ Associate Professor Department of Applied Economics Oregon State University 200A Ballard Ext. Hall Corvallis, OR 97331 lewisda@oregonstate.edu

${ }^{3}$ Professor, Department of Agricultural and Applied Economics, University of Wisconsin - Madison 427 Lorch St. Madison, WI 53706 rwproven@wisc.edu
} 


\section{Introduction}

The conservation of open space is widely used as a policy tool to mitigate urban sprawl, protect habitat, and provide ecosystem services. One consequence of conserved open space that has received attention is the land market feedback effect on the development of neighboring lands. Conserved open space provides local public goods amenities to nearby households, thereby increasing urban rents relative to agricultural/forest rents and potentially increasing nearby development (Wu and Plantinga 2003; McConnell and Walls 2005). In a high-profile descriptive analysis at the U.S. national level, Radeloff et al. (2010) showed that some of the highest rates of housing growth in the U.S. were on lands close to protected federal lands such as wilderness areas, national parks, and national forests. Similar evidence of the developmentattracting effects of conserved open space has been found in more localized econometric studies of the development of agricultural lands (Bockstael 1996; Irwin and Bockstael 2004; Walsh 2007; Towe et al. 2008). In contrast to the development of land currently in agricultural or forest use, the effect of conservation on the further development of land already in residential use is ambiguous because conservation can increase the rents to further developing residential land and the rents to keeping residential land in its current density (Lewis et al. 2009).

In this paper we investigate the effect of conserving open space on the net change in local development. The net effect of conservation on local development depends on the amount of land directly protected from development, and on the amount of development that may occur on neighboring unprotected private land in response to conservation. Empirical examination of the net local change in development arising from past land conservation requires a modeled counterfactual of a local landscape's evolution in lieu of formal land conservation. Quantifying the net change in development arising from conserving land is found by taking the difference in 
the amount of the landscape development with and without conserved open space. We use a novel econometrically-based landscape simulation to generate the counterfactual landscape.

We quantify the retrospective marginal effects of multiple active land conservation programs on net development in Door County, Wisconsin. We construct a new and unique micro panel data set of legally subdividable private parcels from 1978 to 2009 , with the spatial evolution of parcel subdivision followed in approximately three-year intervals. The data include the spatial locations of all conserved open space in the county, as well as the dates of protection, which allows us to construct a time-varying measure of the distance of each private parcel to the nearest conserved open space. We construct parcel and zoning data sets from local planning department GIS layers for 1999-2009 and by digitizing historical paper plat maps dating back to 1978. The full dataset containing the spatial-temporal pattern of land subdivision and conservation is used to estimate an econometric model of land conversion at the parcel-level. Descriptive statistics indicate that the subdivision rate and density of new developments is higher on lands closer to conserved open space. We model the decision about whether to subdivide a parcel (the subdivision decision), and how many parcels to create conditional on subdivision (the density decision). We use a Heckman framework to account for selection bias that arises because density decisions are only observed on those parcels where subdivision occurs, and because the density decision necessarily shares common unobservables with the subdivision decision (Heckman 1979; see Lewis et al. 2009 for a previous application). This econometric framework is more detailed than binary development models because it explicitly accounts for the density decision, a necessary feature of an empirical analysis of the net development change arising from land conservation. 
An important contribution of the analysis is describing an endogeneity problem associated with estimating the effects of conserved open space on neighboring development and devising a spatial-panel data strategy for identification. The existing econometric literature investigating the effect of conservation on nearby development has not fully examined, nor found a solution to, the endogeneity of land conservation (Bockstael 1996; Irwin and Bockstael 2004; Newburn and Berck 2006; Walsh 2007; Towe et al. 2008; Lewis et al. 2009). There are two aspects to the endogeneity problem. First, the location of land conservation is driven by political-economic factors that also drive land markets, as conservation may be driven by cost factors (Ferraro and Pattanayak 2006) and by the scenic beauty of the surrounding landscape. For instance, scenic or special landscapes (e.g. shorelines, rolling hills, overlooks) are often attractive for development and are often targeted by conservation agents (such as governments and NGOs) for protection, recreation and other conservation purposes. Indeed, the understanding that such locations are more likely to be developed is itself a possible driver of the timing of protection by conservation agencies. Second, the communities that invest in land conservation may also invest in other local public goods such as schools, recreation and arts programs, which affect the land subdivision decision. Identification challenges arise because political-economic factors and other local public goods are difficult to measure, and often remain unobserved in econometric analysis.

Many conventional identification strategies are not easily used to investigate the effects of conserved open space on neighboring development. As a point of reference, the ideal identification strategy would feature a randomized experiment where conserved open space is randomized in size and location across landscapes. In the absence of randomization, a potential identification strategy is to use knowledge of the rules governing conservation decision-making 
by conservation agents. However, open-space stocks tend to accumulate over long periods of time with heterogeneity in conservation rules both across different conservation agencies, and over time within the same agency or NGO. ${ }^{\mathrm{i}}$ Such heterogeneity makes it challenging to generate anything but an extremely weak instrument. Alternatively, spatial discontinuities in policies have been used to examine land-use questions related to zoning policy (e.g. Butsic et al. 2011; Dempsey and Plantinga 2013). Such a discontinuity design is not easily adopted to an analysis of the effects of conserved open space on neighboring development because the treatment effect -distance between varying sizes of open space and a parcel—is continuous rather than binary, and the lack of excludable access to the benefits of most conserved open space ensures that there is typically no discontinuity to exploit.

We develop a panel-data identification strategy that is motivated by the possibility that conservation location decisions are influenced by some of the same unobserved variables that influence development decisions. Given our use of a spatial landscape simulation that requires development probabilities to be bound between zero and one, we use non-linear binary models of subdivision. An obvious identification strategy is to eliminate parcel fixed effects, but in the context of a nonlinear binary model doing so generates biased estimates of marginal propensities to subdivide, thereby eliminating the opportunity to simulate the evolution of the landscape with and without particular open-space parcels, which is a prime motivation of the research. As an alternative, we approximate a parcel fixed effects strategy by using correlated random effects to control for unobservables such as landscape-level scenery or other locational idiosyncrasies that are invariant over the time frame of the analysis. In contrast to earlier efforts with similar types of data (e.g. Lewis et al. 2009), significant temporal variation in conserved open space is found in our dataset and crucial to our identification strategy and post-estimation simulation design. We 
also include community fixed effects interacted with time fixed effects to control for timevarying community characteristics that influence both development-attracting public goods and conserved open space. Consistent with the idea that conservation creates local amenities, our econometric results indicate that new conservation land increases the probability of neighboring subdivision in our study region, but has mixed effects on the density of newly developed lots.

A second contribution is our integration of the estimated econometric parcel-level subdivision probabilities and density expectation rules into a spatial landscape simulation model to examine the retrospective marginal effects of the creation of conserved open space on net local development. We examine counterfactual landscapes by systematically removing, one at a time, the conservation designation of conserved open space during our study period from 1978 to 2009, and calculating the effect on the expected development density for each conserved open space in the study area. We conduct the analysis one conserved open space at a time to examine a series of marginal changes in conservation. This approach avoids altering the local hedonic land price functions (Walsh 2007; Klaiber and Phaneuf 2010), an issue that is beyond the scope of the present analysis. Prior econometric landscape simulation efforts have examined hypothetical future landscape outcomes in response to a policy (Lewis and Plantinga 2007; Lohse et al. 2008; Nelson et al. 2008) or average marginal effects of a policy on a parcel's development probability (Lewis et al. 2009). In contrast, our econometric-simulation method can examine spatial heterogeneity in the retrospective marginal effects of an active amenity generation policy on the pattern of landscape change. Spatial heterogeneity in our application arises from i) the size of conserved open space, ii) the presence of nearby conserved open space substitutes, and iii) the configuration of nearby developable agricultural and residential lands. The combined econometric-simulation methodology we develop could be used in other 
applications to examine the effects of policy-generated amenities or dis-amenities on the spatial structure of landscape development.

Our simulation results indicate that $79 \%$ of parcels conserved as open space between 1978 and 2009 generate a reduction in net development rather than an increase. Approximately $57 \%$ of conserved open space had minor (between $-10 \%$ and $+10 \%$ ) impacts on net development. This important new result - which to our knowledge has not been shown in prior literature indicates that most conserved open space in this region simply reallocated development within a small neighborhood (within a half-mile radius) rather than altering the total amount of development in that neighborhood. We explore the landscape conditions that may lead to conservation having either a positive or negative effect on local development.

\section{Theoretical considerations}

We begin by sketching some key theoretical issues to motivate our reduced-form model of a landowner's binary decision to develop a parcel, which we will refer to as the decision to subdivide. Following classical land rent theory (e.g. Capozza and Helsley 1989), a landowner chooses to subdivide parcel $i$ at time $t$ if the rental value of subdividing exceeds the rental value of not subdividing:

$$
R^{D}\left(x_{i t}\right)+\varepsilon_{1 i t}>R^{O}\left(z_{i t}\right)+\varepsilon_{\text {Oit }}
$$

where $\left(R^{D}\left(x_{i t}\right)+\varepsilon_{1 i t}\right)$ denotes the rental value of land in its developed state and $\left(R^{O}\left(z_{i t}\right)+\right.$ $\left.\varepsilon_{\text {Oit }}\right)$ denotes the rental value of land in its original state. The vectors $x_{i t}, z_{i t}$ represent observable parcel characteristics affecting the value of subdivided and un-subdivided land, respectively, including proximity to conserved open space, and $\varepsilon_{1 i t}, \varepsilon_{\text {Oit }}$ are components of the land rent function observed by the landowner but not observed by the analyst. Importantly, the 
value $\left(R^{D}\left(x_{i t}\right)+\varepsilon_{1 i t}\right)$ assumes the development density that maximizes the rental value of the subdivided parcel, as described below. The decision rule in equation (1) describes the profitmaximizing decision when subdivision is irreversible, under the assumption that the time path of $R^{D}$ crosses the time path of $R^{O}$ from below and, once higher, stays higher.

Following Lewis et al. (2009), the rental value of land in its developed state is the solution to the problem of choosing a development density $m$ (e.g. number of lots per unit of land) to maximize the rental value of land conditional on subdivision:

$$
R^{D}\left(x_{i t}\right)+\varepsilon_{1 i t}=\max \left\{D R_{m}\left(x_{i t}\right)+\varphi_{i m t}\right\}
$$

where $D R_{m}\left(x_{i t}\right)$ is a density-specific rental value that is a function of parcel observables, and $\varphi_{\text {imt }}$ is a density-specific variable observed by the decision-maker but not by the analyst. The optimal density for landowner $i$ in time $t$ is,

$$
m^{*}\left(x_{i t}, \varphi_{i m^{*} t}\right)=\operatorname{argmax}_{m}\left\{D R_{m}\left(x_{i t}\right)+\varphi_{i m t}\right\}
$$

where $\varphi_{i m^{*} t}$ is the value of $\varphi_{i m t}$ for the density choice $m^{*}$ that maximizes $D R_{m}\left(x_{i t}\right)+\varphi_{i m t}$. Importantly, the rental value of land conditional on subdivision equals the maximum densityspecific rental value of the land, such that $R^{D}\left(x_{i t}\right)=D R_{m^{*}}\left(x_{i t}\right)$ and $\varepsilon_{1 i t}=\varphi_{i m^{*} t}$. This relationship implies that the unobserved determinants of optimal density $\left(\varphi_{i m^{*} t}\right)$ are necessarily correlated with the unobserved determinants of the decision to subdivide $\left(\varepsilon_{\text {Oit }}-\varepsilon_{1 i t}\right)$. Therefore, empirical modeling of the density decision is subject to sample selection bias - only those landowners who choose to subdivide are observed to pick a density.

In examining the effect of open space on development, we distinguish between developing agricultural parcels and residential parcels. When modeling the conversion of agricultural parcels to residential development, the rental value of developed (residential) and undeveloped (agricultural) parcels are generally functions of different variables $\left(x_{i t} \neq z_{i t}\right)$. For 
example, the rental value of agricultural land is typically influenced by soil quality and local agricultural labor markets, whereas the rental value of residential land is influenced by the distance to urban centers and retail services, crime rates, school quality, and so forth. In order to introduce open space into the landowner's problem, we assume that conserved open space provides use value that is inversely dependent on distance (Wu and Plantinga 2003). As such, we specify $s_{i t}$ as the distance of parcel $i$ to the nearest conserved open space in time $t .{ }^{\mathrm{ii}}$ Conserved open space is defined here as land directly preserved from development by a government agency or a non-profit land-trust, and includes designations such as parks and easements but does not include private open space or forests that can be developed in the future. ${ }^{\text {iii }}$ To the extent that a reduction in the distance to conserved open space $\left(s_{i t}\right)$ has little or no effect on the rental value of agricultural land ( $s_{i t} \notin Z_{i t}$ ), but a positive effect on the rental value of residential land ( $s_{i t} \in$ $x_{i t}$ ), being closer to conserved open space increases the probability of agricultural conversion to residential use (Chestire and Sheppard 1995, Geoghegan et al. 2003, Carrión-Flores and Irwin 2010, Irwin 2002)

The effect of distance to the nearest conserved open space on further development of land already in residential use is more complicated, because now this variable is an argument of both $R^{O}(\cdot)$ and $R^{D}(\cdot)$, and so its effect depends on how open space and the size of a private parcel interact to affect the parcel's rental value; they could be substitutes, complements, or neither (separable). If distance to open space and the size of a private parcel are separable, then new open space adds the same value to the original "parent" parcel as to each "offspring" parcel after subdivision, in which case open space increases the probability of development of local private parcels. In other words, even if open space has no effect on the marginal value of other inputs in the rental value of a residential parcel, it induces greater residential density. This emphasizes the 
causal "lean" of open space towards greater local development, even in the case where land is already in residential use. If distance to open space and private parcel size are monotonically substitutes, then in the context of our theoretical model it increases both the probability that a parcel is subdivided and $m^{*}$, the number of parcels created upon subdivision. On the other hand, if distance to open space and parcel size are monotonically complements, then new open space could decrease both the probability that a parcel is subdivided and $m^{*}$, though the effect is ambiguous (Lewis et al. 2009).

The evidence in the empirical land-use literature on the relationship between conserved open space and the size of private parcels is mixed, with some papers finding a separable or substitutes relationship (Kopits et al. 2007; Cho et al. 2010), a complementary relationship (Lewis et al. 2009), or a complementary relationship at small scales and a substitutes relationship at larger scales (Abbot and Klaiber 2010).

\section{Econometric framework and application}

The landowner's decision problem is modeled in terms of (1) a binary decision to subdivide a parcel, $y_{i t}=1$; and (2) a density decision to create $m_{i t}$ new lots per acre on parcel $i$ in municipality $k(i)$ at time $t$, conditional on subdivision. With panel data, the subdivision decision is observed repeatedly over time for a given parcel until subdivision transpires, whereas the density decision is observed only during the period in which subdivision occurs. Because conserved open space can have different marginal effects on the development of agricultural land versus further development of existing residential land, we separately estimate parameters for development on agricultural land and development on existing residential land.

Our econometric specification of the landowner subdivision and density decisions presented in equations (1)-(3) is the following: 


\section{Latent net land value of subdivision}

$$
y_{i t}^{*}=f\left(s_{i t}\right)^{\prime} \delta+w_{i t}^{S^{\prime}} \beta+c_{i}+\tau_{t}+\mu_{k(i), t}+\eta_{i t}^{S}
$$

\section{Density decision:}

$$
\ln m_{i t}=f\left(s_{i t}\right)^{\prime} \gamma+w_{i t}^{D^{\prime}} \alpha+\tau_{t}+\mu_{k(i), t}+\eta_{i t}^{D} ; \quad \text { if } y_{i t}=1
$$

where $f\left(s_{i t}\right)$ is a polynomial function of the distance to open space variable $\left(s_{i t}\right)$ and $w_{i t}^{S}, w_{i t}^{D}$ include the other parcel characteristics in Table I that affect the net land value of subdivision and the rental value of land in its developed state, respectively. The terms $\eta_{i t}^{S}$ and $\eta_{i t}^{D}$ are random variables, correlated with each other through a bivariate normal distribution. The other three variables $\left(c_{i}, \tau_{t}, \mu_{k(i), t}\right)$ denote unobservables that are potential sources of endogeneity and attendant identification challenges which are discussed in section 3.5. Parameters in equation (4) can be estimated with a binary Probit model, where subdivision $\left(y_{i t}=1\right)$ is observed when the net land value of subdivision $\left(y_{i t}^{*}\right)$ is positive. Parameters in equation (5) can be estimated with linear regression, accounting for the sample selection problem which arises from correlation between $\eta_{i t}^{S}$ and $\eta_{i t}^{D}$. Because our data includes repeated three-year snapshots of the landscape, subdivision that occurs sometime in the three-year interval beginning in time $t$ is a function of covariates measured at time $t$.

\subsection{Study area and data}

The model is applied to Door County, Wisconsin, on the upper end of a peninsula with 300 miles of coastal shoreline along Lake Michigan that is home to about 30,000 year-round residents and attracts about 2 million tourist visits per year (U.S. Census Bureau, 2012; Door County Parks and Open Space, 2011-2015). The peninsula is also noted for its large concentration of rare species and exceptionally high conservation value (Merryfield et al. 2000). 
Open space acquisition has long been a primary environmental management tool employed by conservation agents.

The data used in the econometric analysis of Door County land development are composed of three major GIS panel data sets: conserved open space layers; parcel layers; and zoning layers. We developed the first data set by working with the Door County Planning Department and Land Information Office, and the Nature Conservancy, ultimately constructing time-indexed GIS layers for all 275 current parcels of conserved open space (federal, state and local parks, Nature Conservancy easements, and Door County Land Trust lands). Conserved open space designations include community, state, town and village parks and nature preserves, conservation easements $^{\mathrm{iv}}$ (including Managed Forest Law (MFL) open and closed lands ${ }^{\mathrm{v}}$ ), federal preserves, university land and other lands used for education purposes, Scouts land, designated scenic corridors, and open space in clustered residential subdivisions (property owned in common). We constructed the second data set from GIS layers for 1999-2009 and paper plat maps provided by the Door County Planning Department for the period before $1999 .{ }^{\text {vi }}$ The data identify every parcel of land from 1978-2009 in approximately three-year intervals. ${ }^{\text {vii }} \mathrm{We}$ constructed the third data set from historical zoning maps provided by the Door County Planning Department. The data identify the zoning districts and minimum lot size requirements for every parcel during the study period. Applying these data sets in an econometric analysis of the subdivision decision required three data preparation steps: classifying parcels as either agricultural or residential; determining whether a parcel is legally subdividable, and if so, whether and when subdivision took place during the study period; and developing the observable parcel characteristics relevant to the subdivision decision problem.

\subsection{Classifying a parcel as agricultural versus residential}


Ideally a parcel is classified as agricultural based on evidence that it is in fact used in agriculture. Unfortunately our data do not include a temporal record of the agricultural disposition of each parcel in the dataset; our only direct evidence of the agricultural disposition of a parcel is a 1992 land use inventory. Instead we relied on the zoning history of the parcel to identify it as agricultural versus residential. Zoning classification and the actual land use appear to be highly correlated in this study region. In particular, farming in "Exclusive Agricultural Zones" qualify farmers for income tax credits in Wisconsin, so there is a strong economic incentive for working farms to be located in these zones. Furthermore, only $4.6 \%$ of parcels that are zoned agricultural in the 1992 zoning map are classified as residential in Door County's 1992 land-use inventory, indicating that parcels zoned agricultural are unlikely to be in residential use. Also, the similarity between the total acreage of Door County's land zoned agricultural and the acreage of land in agricultural use according to the U.S. Census of Agriculture (reported in the appendix, Table A1) indicates that parcels zoned residential are unlikely to be in agricultural use $^{\text {viii }}$.

We observe parcels from 1978 to 2009 and use this time frame to classify parcels as agricultural or residential. Parcels are considered to be agricultural parcels from the time they are zoned agricultural ${ }^{\mathrm{ix}}$ to the time they subdivide and are rezoned as residential ${ }^{\mathrm{x}}$ during the observed study period (1978-2009). If an agricultural parcel subdivides without being rezoned during the study period, then we assume that this parcel was subdivided for purposes other than construction of new buildings and it remains in our agricultural sample. If an agricultural parcel is rezoned without subdividing during the study period then we assume that the parcel was not actually developed and remains in our agricultural sample. Parcels are considered to be residential parcels after an agricultural parcel subdivides and switches to residential zoning, or if 
a parcel is zoned residential in the current period and was not zoned agricultural in the previous years of our study period.

\subsection{Defining subdividable parcels}

A parcel is legally subdividable when it is greater than twice the minimum lot size. A parcel subdivision is considered development of agricultural land when a legally subdividable agricultural parcel subdivides and all subsequently created parcels are completely rezoned residential. ${ }^{\mathrm{xi}}$ This conservative definition does not define any development as occurring for cases where subdivision of a large farm creates a large agriculturally zoned parcel and some small parcels that are zoned residential. We investigated a more liberal definition that defines development as occurring when subdivision on an agricultural parcel creates at least one new parcel zoned residential. Results are robust to either definition of development, and so we use the conservative standard that development on agricultural lands only occurs when the subdivided parcel completely rezones to residential. A parcel subdivision is considered further residential development when a legally subdividable residential parcel subdivides.

Table II details the subdivision that occurred in each period on both agricultural and residential parcels. ${ }^{\text {xii }}$ The dataset is an unbalanced panel, with parcels dropping from the sample when they are less than twice the size of the minimum lot size requirement and thus are unable to subdivide further. The number of subdividable parcels in our datatset can decrease over time as parcels subdivide and become too small to legally subdivide further and if zoning regulations become stricter. On the other hand, the number of subdividable parcels can increase over time as subdivision increases the total number of parcels some of which remain subdividable and if zoning regulations become less strict. The number of subdividable agricultural parcels goes from 2,948 parcels in 1978 to 884 parcels in 2005 . The number of subdividable residential parcels 
goes from 2,641 parcels in 1978 to 3,409 parcels in 2005. If a parcel is subdivided into multiple lots that remain legally subdividable, the new parcels enter the data set in the period after their creation. Table III details the average number of lots created upon subdivision. Figure 1 shows the spatial distribution of both subdivision and conserved open space between 1978 and 2009 and Table IV details the additional open spaces by size and year.

\subsection{Variables representing parcel characteristics}

Summary statistics for the variables used in estimation are presented in Table I. Of greatest interest in this study are the time-varying variables related to open space. The primary open space variable of interest is the distance to conserved open space (open_dist). While there are many alternate measures of conserved open space - such as the percentage of open space within a pre-defined radius ${ }^{\text {xiii }}$ - we use distance because it is (1) simple and transparent to measure, and (2) it has extensive support in the literature (e.g. Tyrvainan and Miettinen 2000; Anderson and West 2006; Sander and Polasky 2009; Fan et al. 2015). We measure distance from each private parcel boundary to the nearest boundary of a conserved open space. The value of this variable changes over time as new open space is created. There has been a substantial increase in conserved open space from 1978 to 2009 in Door County due to increased efforts by the Nature Conservancy, the creation of the Door County Land Trust in 1986, and the expansion and addition of new county and town parks. The mean distance to open space decreased from 0.95 miles in 1978 to 0.48 miles in 2005 . Tables II and III suggest that private parcels within a half-mile of open space are more likely to develop and at higher density than private parcels further than a half-mile. Recent hedonic literature suggests that the capitalization of conserved open space into land values is highly localized and potentially non-linear (Acharya and Bennett 2001; Thorsnes 2002; Irwin 2002; Walsh 2007). To allow the marginal effect of a reduction in 
distance to open space on development to be downward sloping and flexibly non-linear in distance, we specify the effect of distance to open space on the probability and density of development as a $p^{\text {th }}$ order polynomial and test for the appropriate order in section 4.

Recent literature has found evidence that open space is a heterogeneous good with the value of open space depending critically on the type of open space considered (Klaiber and Phaneuf 2010; Anderson and West 2006; Irwin 2002). Our analysis examines heterogeneity in the size and proximity to preserved open space. We allow the effect of the distance to open space to vary by the size of the closest open space by including in the model the interaction between open_dist and the size of the conserved open space (open_size). We also include a triple interaction term between open_dist, open_size, and a dummy variable (open_big) that equals one if the nearest open space is in the $95^{\text {th }}$ percentile of open space size (greater than 3,608 acres), to capture any nonlinearities in the effect of large state parks.

The only other time-varying variables included in the model are the zoned minimum lot size in acres (minlot) ${ }^{\text {xiv }}$ and split. Minlot has changed substantially in Door County, Wisconsin over our sample timeframe, 1978-2009. We observe a wide range of agricultural minimum lot sizes from a low of 0.23 acres to a high of 35 acres. Residential minimum lot sizes range from a low of 0.23 acres to a high of 5 acres. We include a quadratic specification for minimum lot size to capture potential nonlinearities ${ }^{\mathrm{xv}}$. We explore these zoning ordinances more in a supplementary appendix, including a categorical specification for minlot. Split is used in the subdivision model only, and indicates whether a parcel can be split into two parcels at most due to the minimum lot size constraint captured by minlot. Split is used to account for the fact that splitting a small parcel is often not economically sensible due to the presence of an existing residential structure in the middle of the lot. 
Time-invariant variables concerning the locational characteristics of a parcel include whether the closest shore is Green Bay or Lake Michigan (bay_dummy), the distance to that closest shore (shore_dist), ${ }^{\mathrm{xvi}}$ and the distance to the closest city center, Green Bay (GB_dist), which is included to capture potential commuting costs to the region's largest employment base. Time-invariant variables concerning a parcel's physical potential for development include parcel size in acres ( area and $\left.\operatorname{area}^{2}\right)^{x v i i}$, the presence of steep slopes (pslope), the potential for frequent flooding (pflood), and a rating that indicates limited development of basements (pbsmnt) (from the U.S. Department of Agriculture, Natural Resources Conservation Service's Soil Survey Geographic (SSURGO) database for Door County, Wisconsin in 2009).

\subsection{Identification strategy}

Identification challenges arise if open space location decisions are influenced by some of the same unobserved variables that influence development decisions. The endogenity of proximity to conserved open space arises primarily for two reasons, both of which apply to three types of unobservables correlated with open space formation in our model $\left(c_{i}, \tau_{t}, \mu_{k(i), t}\right)$. The first is that developers and conservation agents may respond to the same unobservable variables. For instance, scenic landscapes are often attractive for development and also for protection, recreation and other purposes favored by governments and NGOs. In our study region, for instance, views of Lake Michigan are important time-invariant amenities for both homeowners and conservation agents. Conversely, a budget-strapped agency might focus preservation efforts on cheaper land that is undesirable for development, such as wetlands (Ferraro and Pattanayak 2006).

The second reason that conserved open space could be endogenous is that the agency creating open space may be engaged in other unobservable activities that are temporally and 
spatially correlated with the creation of open space, and developers are responding to these other unobservable activities. For example, local governments that invest more in conserved open space also tend to invest more in local public goods such as schools, recreation and arts programs, and other public goods that attract migrants. Local public goods make development more attractive, and to the extent such local public goods are typically not easily quantified, or not quantified without significant error, in a statistical model the relationship between open space and development can appear to be greater than it is.

To address these two cases of endogeneity, we take advantage of the panel structure of our data. We include time-indexed fixed effects $\tau_{t}$ in both the subdivision and density decision models to control for spatially-invariant changes in the general economic environment over the last thirty years, such as housing bubbles and busts, mortgage rates, and interest rates. Addressing the other two types of unobservables is a bit more involved and described below.

\subsubsection{Addressing time-invariant parcel unobservables in the subdivision decision}

Because parcels are observed over time until they subdivide, it is conceivable to control for $c_{i}$ in the subdivision model. An obvious approach is a linear probability model (LPM), which often generates good approximations of parameters and average partial effects. However, we do not enlist the LPM because it does not restrict the predicted probabilities to be between zero and one, which is required for our landscape simulation exercise.

A Logit model keeps predicted probabilities between zero and one, and parcel-specific fixed effects (FE) can be eliminated from a Logit model of subdivision by conditioning the probability of parcel subdivision on the cumulative value of the dependent variable (the binary choice variable to subdivide) over the study period and using conditional maximum likelihood methods (Wooldridge 2010). Unfortunately such an FE Logit model does not generate unbiased 
estimates of the marginal effects or the predicted probabilities of subdivision, which depend on the un-estimated parcel-specific fixed effects. Consequently, as is the case with the LPM model, it is not suitable for our landscape simulation exercise.

The correlated random effects (CRE) model overcomes the shortcomings of the FE model in non-linear applications in a way that allows its use for the landscape simulation. In the current context, the CRE model frames the correlation between open space and unobservables as fully captured by the time averages of the explanatory variables. This is an intuitive specification stating, for instance, that if the (unobserved) scenic value of an area increases both the probability of subdivision and the local amount of open space, then the average distance to open space over time serves as a good instrument for the effect of scenery on the probability of subdivision; areas with great scenery are closer to open space on average throughout the study period. Formally, the correlated random effects enter the subdivision model through parcelspecific effects, $c_{i}$, and the Chamberlain (1980) conditional normality assumption:

$$
c_{i}=\psi+\bar{s}_{i} \zeta+\bar{w}_{i}^{\prime} \xi+a_{i}
$$

where $\bar{s}_{i}=T^{-1} \sum_{t=1}^{T_{i}} s_{i t}, \bar{w}_{i}=T^{-1} \sum_{t=1}^{T_{i}} w_{i t}$ are the time averages of the open space and other explanatory variables; the random effects, $a_{i}$, are assumed to be distributed normally, $a_{i} \mid w_{i} \sim \operatorname{Normal}\left(0, \sigma_{a}^{2}\right)$; and $\sigma_{a}^{2}$ is the conditional variance of $c_{i}$. The primary identifying assumption of the correlated random effects model is $E\left[c_{i} \mid f\left(s_{i t}\right), w_{i t}^{S}, \tau_{t}\right]=\psi+\bar{s}_{i} \zeta+\bar{w}_{i}^{\prime} \xi$. Since the density decision is only observed once for each lot upon subdivision, we lack the true panel variation we need to include $c_{i}$ in the density equation, and so we are implicitly assuming that $c_{i}$ captures parcel unobservables that are invariant across different densities within a given parcel. $^{\text {xviii }}$ 


\subsubsection{Addressing municipality/time unobservables}

Some unobservables that likely affect the development decision and may be correlated with open space, such as school quality, taxes, tourist amenities, and community development, vary over both time and space. For example, towns that provide high levels of open space are also likely to provide high levels of these other public goods, which affect the development decision. On the other hand, conservation agencies may target towns that have lower quality public goods and thus cheaper land. We control for these time- and spatially-varying effects by including in our model a full set of interactions between the 19 municipalities/towns in our study $\operatorname{area}^{\mathrm{xix}}$ and time dummies $\left(\mu_{k(i), t}\right)$.

This strategy leaves time-varying unobservables within a municipality that affect both the location of conserved open space and the subdivision and density decisions; in other words, time-varying unobservables at a spatial scale too small to be captured by the variables $\left(\mu_{k(i), t}\right)$. An example is that conservation agencies may wish to create clustered or connected conservation areas. In this case, new open space could be systematically placed near existing open space within a municipality, leading to potential simultaneity bias between open space and development decisions. To examine whether this may be a problem, we test for complete spatial randomness (CSR) in the location of conserved open space within each municipality in 2009 using a common transformation of Ripley's K-function, L(d), in the software ArcGIS. ${ }^{\mathrm{xx}}$ We fail to reject the null hypothesis (5\% level) of CSR of conserved open space for 16 of the 19 municipalities, with the exceptions being the Town of Sturgeon Bay (where open space was more dispersed than CSR), and the Towns of Sevastopol and Gibraltar (where open space was more clustered than CSR) ${ }^{\mathrm{xxi}}$. Thus, it appears unlikely that any bias would result from systematic clustering of open space. 
Another potential source of bias is our omission of developable - as opposed to conserved - local open space as an independent variable affecting the probability of subdividing. Omitting developable open space could bias our results if developable open space is correlated with conserved open space and affects the probability of development. We have three responses to this concern. First, our municipality/time fixed effects likely control for the most important variation in developable open space, which is across communities. Second, hedonic modeling has found evidence that conserved open space has a significantly greater spillover effect on land values than developable open space (Irwin 2002; Geoghegan et al. 2003), so omitting developable open space likely has minimal effects on bias. Third, including an independent variable representing developable open space is arguably a case of "bad control" (Angrist and Piscke 2009, p.64) or "over control" (Wooldridge 2009, p.204) - including control variables that are themselves outcome variables in the research question at hand. In particular, the ceteris paribus nature of our regression exercise is focused on the subdivision effects of a reduction in the distance of a parcel to the nearest open space, holding all other independent variables fixed. But if reducing distance to open space increases a parcel's subdivision probability, then it must also affect neighboring development probabilities such that neighboring developable open space cannot conceptually be held fixed.

\subsection{Econometric estimation results}

Results are presented separately for agricultural and residential parcels because theory predicts the development decision is different for these two types of parcels, and because a likelihood ratio test rejects at the $1 \%$ confidence level the null hypothesis that all coefficients are the same for agricultural and residential parcels. As argued in section 3.4, for the open space variable of primary interest -the distance of a parcel to the nearest conserved open space - we 
include polynomial functions to capture nonlinearities in the effect of open space based on starting distance. After evaluating multiple orders of a polynomial specification of distance to open space, we use a fourth order polynomial based on a series of likelihood ratio tests across $2^{\text {nd }}$ through $5^{\text {th }}$ order polynomials. However, the results are robust across several different polynomial specifications (third order to fifth order) for parcels close to open space (less than a half-mile). We include an online supplementary appendix to explore i) robustness to alternative specifications of zoning, ii) heterogeneity in development before and after the 1996 to 1999 time period that was affected by Wisconsin's Smart Growth law, and iii) robustness to the inclusion of a variable measuring the percentage of conserved open-space within a half-mile radius of each developable parcel.

We report marginal effects of a quarter-mile reduction in distance to open space on the probability of subdivision (Table V) and the expected density measured as number of lots peracre (Table VI). The full set of parameter estimates are presented in an online supplementary appendix. We report results for five sets of models. The first two use standard Probit models for the subdivision decision, and are distinguished by the absence/presence of the municipality-time interactions term, $\mu_{k(i), t}$ in the subdivision and density decisions. The second two sets use Probit models with correlated random effects (CREs) to account for time invariant unobservables $c_{i}$ in the subdivision decision, and, like the standard Probit models, are distinguished by the absence/presence of $\mu_{k(i), t}$ in the subdivision and density decisions. We also include an intermediate set (Model 4) that uses a Probit model with CREs but time and municipality dummies entered separately instead of interacted $\left(\tau_{t}+\mu_{k(i)}\right)^{x x i i}$. Our preferred model, Model 5 , includes both correlated random effects and municipality-time dummies in the first-stage Probit 
model of subdivision, and municipality-time dummies in the second-stage log-linear model of development density.

For the binary development model (Table V) which has no municipality dummies, municipality-time dummies or correlated random effects (Model 1), adding one of the three controls (shown in Models 2 through 5) changes the point estimate for the marginal effects substantially. For example, adding only municipality-time dummies (Model 2) appears to correct for some upward bias in the primary marginal effect, while adding only correlated random effects appears to correct for some downward bias. However, our preferred specification which adds both municipality-time dummies and correlated random effects (Model 5) generates very similar marginal effect point estimates compared to Model 1, suggesting that the biasreducing effects of including municipality-time dummies and correlated random effects cancel one another out. Results in Table VI indicate that inclusion of municipality-time dummies and correlated random effects has a large impact on the point estimate for marginal effects in the density model.

\subsubsection{Econometric results for agricultural parcels}

There is significant spatial heterogeneity in the effect of conserved open space on the probability of subdivision on agricultural land. Model 5 predicts that the marginal effect of a reduction in the distance to conserved open space on the probability of agricultural subdivision is smaller the farther away a parcel is from open space and statistically insignificant for parcels farther than 0.56 miles away from the closest open space.

For agricultural parcels within a half-mile of conserved open space, Model 5 predicts that a quarter-mile decrease in distance to open space increases the probability of agricultural subdivision in a given time period by approximately 0.9 percentage points on average 
(significant at the $1 \%$ level) and decreases the number of lots per acre by approximately 17 percent (significant at the $1 \%$ level). To put this effect in perspective, in our sample the percent of agricultural parcels that subdivide in each three-year time period varies from 1.28\% (from 1980-1982) to $14.2 \%$ (from 1996-1999) and the number of new lots per acre varies from 0.06 lots per acre (from 1982-1985) to 0.32 lots per acres (from 1996-1999). These results are consistent with previous literature that has found evidence that conserved open space increases the probability of subdivision for agricultural parcels (Bockstael 1996; Irwin and Bockstael 2004; Towe et al. 2008). However, once a landowner decides to subdivide their agricultural parcel and convert it to residential use, a shorter distance to conserved open space decreases the number of residential lots created, which is consistent with a complementary relationship between conserved open space and private lot size (also found in Lewis et al. 2009).

The full results in the appendix show that the size of the nearest conserved open space (open_size) has no statistically significant effect on the probability of subdivision for agricultural parcels but does have a very small but statistically significant effect on the number of lots per acres created upon subdivision. Furthermore, there is no unique effect on the probability of subdivision for agricultural parcels if the closest parcel is exceptionally large (in the $95^{\text {th }}$ percentile of size), as indicated by the non-significance of open_big. However, agricultural parcels whose closest open space is in the $95^{\text {th }}$ percentile of size create approximately 17 percent fewer lots per acre upon subdivision than agricultural parcels whose closest open space is not exceptionally large (statistically significant at the $1 \%$ level).

\subsubsection{Econometric results for residential parcels}

Similar to the results for agricultural parcels, the estimated effect of a reduction in the distance to conserved open space depends on how far a parcel is from open space and the model 
specification. Model 5 predicts that the marginal effect of a reduction in the distance to conserved open space on the probability of residential subdivision is smaller the farther away a parcel is from open space and statistically insignificant for parcels farther than 0.60 miles away from the closest open space.

For residential parcels within a half-mile of conserved open space, Model 5 predicts that a quarter-mile decrease in distance to open space increases the probability of residential subdivision in a given time period by just over one percentage point on average (significant at the $1 \%$ level) and does not significantly change the number of lots per acre To put this effect in perspective, in our sample the percent of residential parcels that subdivide in each three-year time period varies from $1.24 \%$ (from 1987-1990) to $20.4 \%$ (from 1996-1999) and the number of new lots per acre varies from 0.124 lots per acre (from 1980-1982) to 0.622 lots per acres (from 2005-2009). This result is consistent with previous literature that has found evidence that conserved open space and private residential lots are separable or substitutes in a land development model (Kopits et al. 2007; Cho et al. 2010). Results in the appendix for Model 5 show that the average partial effects of open_size and open_big are not statistically significant (at the $10 \%$ level) for residential parcels.

\section{Forecasting with the econometric simulation model}

\subsection{Landscape simulation methodology}

We use parcel-level subdivision probabilities and density expectations from the estimated econometric model in a spatial landscape simulation model to examine the net local change in development arising from designation of new conserved open space. We examine counterfactual landscapes by systematically removing conservation lands (one at a time) created during our study period from 1978 to 2009 . The only private parcels that will be affected by the removal of any given open space are the private parcels whose closest open space is removed. For this 
subset of private parcels, we then calculate the expected parcel densities over time from the year that the conserved open space was created to 2009 , the last year of our data, with the conserved open space removed. Comparing the expected parcel densities from the counterfactual without a given conserved open space to the baseline expected parcel densities with the conserved open space allows us to calculate the net change in development for each parcel of conservation land created between 1978 and 2009. We conduct the analysis one conserved open space at a time to examine a series of marginal changes in conservation. This "one-at-a-time" approach avoids altering the local hedonic land price functions in a manner that is beyond the scope of the present analysis.

Formally, the simulation exercise works as follows:

1. Draw a conserved open space, $o s_{j t}$, from the set of open space, $j \in 1, \ldots, J$, in Door County from year $t=1978, \ldots 2009$, including conserved open space that were added onto existing open space.

2. Draw the set of private parcels for which $o s_{j t}$ is the closest open space, $i \in N_{o s_{j t}}$.

3. Calculate the expected baseline development, $E\left(D_{i}^{0}\right)$, for each parcel $i \in N_{o s_{j t}}$ as:

$$
\begin{gathered}
E\left(D_{i}^{0}\right)=\hat{P}_{i t_{o s}} \cdot A_{i} \cdot \hat{m}_{i t_{o s}}+\left\{\left(1-\hat{P}_{i t_{o s}}\right) \cdot \hat{P}_{i\left(t_{o s+1}\right)} \cdot A_{i} \cdot \widehat{m}_{i\left(t_{o s}+1\right)}\right\}+\cdots \\
+\cdots+\left\{\prod_{t=t_{o s}}^{T-1}\left(1-\hat{P}_{i t}\right) \cdot \hat{P}_{i T} \cdot A_{i} \cdot \widehat{m}_{i T}\right\} ; \quad \forall i \in N_{o s}
\end{gathered}
$$

where:

$\circ t_{o s}$ is the first period in which the conserved open space $o s_{j t}$ is observed;

- $\quad T$ is the last period in our sample, 2009; 
$\circ \hat{P}_{i t}=\operatorname{Pr}\left(y_{i t}=1 \mid \hat{\psi}_{a}+f\left(s_{i t}\right)^{\prime} \hat{\delta}_{a}+w_{i t}^{S^{\prime}} \hat{\beta}_{a}+\bar{s}_{i} \hat{\zeta}_{a}+\bar{w}_{i}^{\prime} \hat{\xi}_{a}+\hat{\tau}_{t, a}+\hat{\mu}_{k(i), t, a}\right) \mathrm{xxiii}$ is the predicted probability that parcel $i \in N_{o s_{j t}}$ subdivides in time $t$;

○ $A_{i}$ is the area (acres) of parcel $i \in N_{o s_{j t}}$;

$\circ \widehat{m}_{i t}=\exp \left(f\left(s_{i t}\right)^{\prime} \hat{\gamma}+w_{i t}^{D^{\prime}} \hat{\alpha}+\hat{\tau}_{t}+\hat{\mu}_{k(i), t}+\hat{\sigma}_{\varepsilon} / 2\right)$ is the expected private lots per acre on parcel $i \in N_{o s_{j t}}$ in time $t$ (see Greene 2012, pp. $81-83$ for predicting the dependent variable when the regression model describes the log of the dependent variable).

4. Sum the expected baseline development across all parcels in which $o s_{j t}$ is the closest open space, $\sum_{i \in N_{o s}} E\left(D_{i}^{0}\right)$.

5. For the counterfactual simulation, convert conserved open space, $o s_{j t}$, to a developable private parcel and calculate the new distance to open space and size of closest open space for parcels whose closest open space has been removed. Repeat step (3) to calculate the counterfactual expected development, $E\left(D_{i}^{1}\right)$.

6. Sum the expected counterfactual development across all parcels in which $o s_{i t}$ is the closest open space, $\sum_{i \in N_{o s} j} E\left(D_{i}^{1}\right)$.

7. The effect of conserved open space $s_{i t}$ on neighboring development will be

$$
\sum_{i \in N_{o s} j t} E\left(D_{i}^{0}\right)-\sum_{i \in N_{o s} j t} E\left(D_{i}^{1}\right)
$$

8. Repeat for each conserved open space created between 1978 and 2009.

This simulation method estimates the effect of each conserved open space on expected neighboring development. We also need to calculate the effect of each conserved open space on expected development within the open space. Conserved open space may spur development on 
neighboring land but it also protects part of a landscape from ever developing. Therefore, the net effect of conservation on local development depends on the amount of land protected, and on the amount of development that may occur on neighboring private land in response to conservation.

In the counterfactual simulations we change a conserved open space that previously could not be developed and allow it to be developed. We use the estimated econometric model to predict counterfactual parcel-level subdivision probabilities and density expectations for each conserved open space as if it had never been conserved in year $t_{o s}$. If the majority of private parcels for which $o s_{j t}$ is the closest open space, $i \in N_{o s_{j t}}$, are agricultural parcels then we use the agricultural model to predict the subdivision probabilities and density expectations, otherwise we use the residential model. We estimate the sum of the expected development for each conserved open space using steps 3 and 4. One additional note is that since our econometric model does not explicitly include measures of neighboring private development as independent variables, then our method is not able to account for potential "tipping effects" whereby development of one parcel causes development of neighboring parcels.

\subsection{Landscape simulation results}

The simulation accounts for spatial heterogeneity of the locational features associated with each conserved open space (e.g. size of the conserved parcel itself, average size of neighboring parcels, proximity to Green Bay and Lake Michigan, etc.). Whether a conserved open space generates an increase or decrease in net development depends on three primary competing effects. First, new conserved open space increases the probability that neighboring parcels subdivide, and so would be expected to increase neighboring subdivision on average. Second, conditional on subdivision, new conserved open space marginally increases the density of developments on existing residential land but decreases density of developments on 
agricultural land. The mix of neighboring residential and agricultural lands will influence the net development effects on neighboring parcels associated with conserved open space (which we will refer to as the spillover effect). Third, a new conserved open space ensures that development on that particular conserved parcel does not happen.

First, we examine the effect of conserved open space on nearby neighboring development only. Results indicate that almost $66 \%$ of all conserved open space parcels increase development on neighboring private parcels. We further disaggregate the spillover effect of conserved open space on neighboring agricultural parcels versus neighboring residential parcels. Of the 198 unique parcels conserved between 1978 and 2009, 81 are the closest conserved open space to at least one agricultural parcel and $44 \%$ of these open spaces increase development on neighboring agricultural parcels. On the other hand, there are 166 open space parcels that are the closest conserved open space to at least one residential parcel and $69 \%$ of these open spaces increase development on neighboring residential parcels.

Then, we investigate the net effect of conservation on local development by including both the effect of conservation on the amount of neighboring development and the effect of each conserved open space on expected development within the open space parcel itself. Figure 2 presents an estimated distribution of the net effects of conserved open space for each open space parcel conserved between 1978 and 2009. The most common effect is that a single parcel of conserved open space generates close to no effect on the net amount of local development, though there is significant heterogeneity. Approximately $57 \%$ of conserved open space had minimal impacts on net development of between $-10 \%$ and $+10 \%$. A total of $79 \%$ of newly conserved open space induced a net reduction in local development, while $21 \%$ of created conserved open space induced a net increase in local development. Here we see the importance 
of conducting the simulation rather than stopping at marginal effects from the econometric model, as simulation results suggest that while conserved open space does increase neighboring development, it is mostly offset by the amount of development prevented on the conserved openspace parcel itself.

To explore which attributes of conserved open space are most important in leading to larger positive net effects on development, we conduct systematic post-simulation analysis. We regress the proportion change in net development when a parcel, $o s_{j t}$, is conserved as open space (compared to the counterfactual when the parcel is developable) on the size of open space, the proportion of private parcels for which $o s_{j t}$ is the closest open space, $i \in N_{o s_{j t}}$, that is in agricultural use, and a measure of the availability of substitutes for the nearest conserved open space. Substitutability is measured as the average change in distance to conserved open space when the open space is removed (see Table VII for summary statistics). We allow this substitutability measure to have a different effect on conserved open space that lowers net development (negative values of the dependent variable) versus conserved open space that increases net development (positive values of the dependent variable) because we hypothesize that the availability of proximate substitute open spaces will lead to a smaller net effect on development. In areas with more conserved open space the addition of one more conserved parcel does not change the distance to open space for many of the nearby parcels and thus the subdivision probabilities and the density decisions do not change significantly. We also include municipality fixed effects to allow for regional heterogeneity.

The results of this post-simulation analysis are reported in Table VIII. The proportion of land that is in agricultural use does not have a statistically significantly effect on the proportion change in net development due to conserved open space. Adding a larger conserved open space 
has a larger effect on total development than adding a smaller new conserved open space parcel (statistically significant at the 5\% level). The size of open space has two opposing effects on the proportion change in net development: (1) larger open space parcels protect more land from being developed within the open space parcel itself; and (2) larger open space parcels have larger neighborhoods and thus, potentially a greater spillover development effect on nearby parcels. In our sample, we find that the later effect dominates and larger open space parcels increase net development more than smaller open spaces. Results also indicate that the presence of substitute parcels of conserved open space is statistically important in determining the net development effect of each conserved parcel (1\% level). Adding a new conserved open space parcel to a neighborhood with more conserved substitutes has a smaller effect on total development than adding a new conserved open space parcel to a neighborhood with few substitutes.

\section{Conclusions}

Our analysis of the effect of conserved open space on neighboring development provides two primary contributions to the land-use literature. First, we develop a joint econometricsimulation method to estimate the local net development change arising from ongoing conservation programs in a growing region. Our econometric method estimates the effects of conservation land on both the probability of subdivision and on the density at which to develop new lots. Our method also applies insights from urban rent theory to account for the fact that conservation land has different effects on neighboring development when considering development on agricultural land versus further development on existing residential land. Our results indicate a mixture of substitutability and complementarity between private lot size and conserved open space that is consistent with prior literature. We examine counterfactual landscapes by systematically removing conserved open space (one at a time) created during our 
study period from 1978 to 2009. Comparing the expected parcel densities from the counterfactual without a given conserved open space to the baseline expected parcel densities with the conserved open space allow us to calculate the net development change arising from each parcel of conserved open space created between 1978 and 2009. We conduct the analysis one conservation parcel at a time to examine a series of marginal changes in conservation.

Our simulation results indicate that $79 \%$ of parcels conserved as open space between 1978 and 2009 generate a reduction in net development rather than an increase. Importantly, $57 \%$ of conserved open space generated between a negative $10 \%$ and positive $10 \%$ change in net development. Thus the primary result - which to our knowledge has not been shown in prior literature - is that most conserved open space in this region reallocated development within a small neighborhood (within a half-mile radius) instead of altering the total amount of development in that neighborhood. It bears emphasis that results from this modeling exercise are ultimately short-run effects; the long run effect of open space conservation on development could be quite different. To see this, consider the hypothetical where in the long run market forces cause residential development to completely displace agriculture from an area, and local conserved open space and private parcel size are substitutes. Starting from a given initial landscape, in this case the long run development equilibrium is full development (no remaining developable parcels). Open space conservation would initially increase the approach to the equilibrium (the short run effect examined here), but lower the amount of land developed in the steady state, with the conserved open space itself acting as the wedge that prevents full development of all parcels initially available for development. Of course, conserving parcels as open space is not the only tool available to society for reducing development in the long run; zoning ordinances, preferential tax treatment for agricultural land, etc. are also options. The 
availability of these tools, and the fact that they are not employed randomly, but rather as responses to development (and expected future development), reinforces the larger point: land conservation efforts may stimulate nearby development in the short run, but this does not imply a "crowded" landscape in the long-run. Developing an understanding of this endogeneity, especially in a dynamic context in which decisions are forward-looking, is a challenging and rich area of future research.

In a sorting analysis of conserved open space in a metropolitan area, Walsh (2007) evaluates the welfare effects of conservation and shows that increasing conservation land leads to a net increase in aggregate development within a metropolitan area. Our approach, in contrast, is reduced-form rather than structural. If the first-order concern of the researcher is to evaluate welfare effects or non-marginal changes in conserved open space, then a structural approach such as Walsh (2007) will be necessary and our reduced-form approach will be insufficient. However, if the first-order research concern is whether small conserved open space purchases increase or decrease net local development, then our reduced form approach provides a simple econometric approach for estimating marginal effects that does not require structural estimation of utility parameters. See Timmins and Schlenker (2009) for a more general discussion of the differences between structural and reduced-form empirical approaches. By evaluating each conserved open space one-at-a-time, our reduced-form microeconometric-simulation approach produces novel insights into heterogeneity in the effect of small open space purchases on net development where identification comes through the panel variation associated with on-going conserved open-space programs. The size of open space and the presence of substitute conserved open space lands appears to be an important driver of this heterogeneity. Conserved open space 
in areas with little existing open space will conserve less land from development than conserving lands in areas with more existing conserved open space.

The second contribution of this manuscript is the use of a long time series of historical plat maps and available GIS layers to create a replicable panel data solution to the problem that conserved open space is endogenous in a land development model. ${ }^{\text {xxiv }}$ Our application involved Door County, Wisconsin from 1978-2009, which might be a unique case study due to its high natural amenity value and also thriving tourist industry. However, given the wide availability of historical parcel maps from both local governments and commercial vendors the creation of such data is possible in many places, at least in the United States. Important for the present analysis, these data allow us to model the density of development. The panel nature of these data allows us to use an identification strategy that is distinguished from prior literature, which generally treats conserved open space as exogenous. We identify and address two sources of endogeneity: (1) the decisions of both developers and conservation agents are influenced by the presence of local, time-invariant unobservables such as scenery and the presence of wetlands, and (2) conservation agents such as municipalities are also involved in the creation of public goods such as schools and police protection that are unobservable in our analysis and affect the development decision. Our results indicate that the estimated effect of open space on local development is sensitive to controlling for local time-invariant unobservable factors and time-varying unobservable factors at the municipality scale. 


\section{References}

Abbot, J.K. and H.A. Klaiber. 2010. "Is All Space Created Equal? Uncovering the Relationship between Competing Land Uses in Subdivisions.” Ecological Economics 70(2): 296-307.

Acharya, G., and L.L. Bennett. 2001. "Valuing Open Space and Land-Use Patterns in Urban Watersheds.” Journal of Real Estate Finance and Economics 22(2/3): 221-237.

Advisory Committee on City Planning and Zoning of the US Department of Commerce. 1928. A Standard City Planning Enabling Act (SCPEA). Document Number: BH111. Assessed from http://www.planning.org/growingsmart/pdf/CPEnabling\%20Act1928.pdf

Anderson, S.T. and S.E. West. 2006. “Open Space, Residential Property Values, and Spatial Context.” Regional Science and Urban Economics 36(6): 773-789.

Angrist, J.D. and J-S. Pischke. 2009. Mostly Harmless Econometrics: An Empiricist's Companion. Princeton University Press. Princeton, New Jersey.

Bockstael, N.E. 1996. "Modeling Economics and Ecology: The importance of a Spatial Perspective.” American Journal of Agricultural Economics 78(5): 1168-1180.

Butsic, V., Lewis, D.J., and L. Ludwig. 2011. “An Econometric Analysis of Land Development with Endogenous Zoning.” Land Economics 87(3): 412-432.

Capozza, D.R. and R.W. Helsley. 1989. "The Fundamentals of Land Prices and Urban Growth" Journal of Urban Economics 26: 295-306.

Carrión-Flores, C. and E.G. Irwin. 2010. "Identifying Spatial Interactions in the Presence of Spatial Error Autocorrelation: An Application to Land Use Spillovers.” Resource and Energy Economics 32: 135-153.

Chamberlain, G. 1980. “Analysis of Covariance with Qualitative Data.” The Review of Economic Studies 47(1): 225-238. 
Chestire, P. and S. Sheppard. 1995. "On the Price of Land and the Value of Amenities." Economica 62(246): 247-267.

Cho, S-H., D.M. Lambert, R.K. Roberts, and S.G. Kim. 2010. "Moderating Urban Sprawl: Is There a Balance between Shared Open Space and Housing Parcel Size?” Journal of Economic Geography 10: 763-783.

Dempsey, J.A. and A.J. Plantinga. 2013. "How Well Do Urban Growth Boundaries Contain Development? Results for Oregon Using a Difference-in-Difference Estimator.” Regional Science and Urban Economics 43: 996-1007.

The Door County Land Trust. "Places We Protect." http://doorcountylandtrust.org/places_we_protect.htm

Door County Parks and Open Space, 2011-2015. Prepared by the Door County Parks Department.http://map.co.door.wi.us/parks/DC\%20Parks\%20\&\%200pen\%20Space\%20 Plan\%202011-2015.pdf

Fan, Q., Hansz, J.A., and X. Yang. 2015. "The Pricing Effects of Open Space Amenities." Journal of Real Estate Finance and Economics (In Press) DOI: 10.1007/s11146-0159508-1.

Ferraro, P.J. and S.K. Pattanayak 2006. "Money for Nothing? A Call for Empirical Evaluation of Biodiversity Conservation Investments.” PLOS Biology 4(4): 0482-0488

Geoghegan, J., L. Lynch, and S. Bucholtz. 2003. “Capitalization of Open Spaces into Housing Values and the Residential Property Tax Revenue Impacts of Agricultural Easement Programs.” Agricultural and Resource Economics Review 32: 33-45.

Greene, W. 2008. Econometric Analysis, sixth edition. Prentice-Hall. New York, NY. Heckman, J. 1979. “Sample Selection Bias as a Specification Error.” Econometrica 47: 153-161. 
Irwin, E.G. 2002. "The Effects of Open Space on Residential Property Values.” Land Economics 78(4): 465-480.

Irwin, E.G. and N.E. Bockstael. 2001. "The Problem of Identifying Land Use Spillovers: Measuring the Effects of Open Space on Residential Property Values.” American Journal of Agricultural Economics 83(3): 698-704.

Irwin, E.G. and N.E. Bockstael. 2004. "Land Use Externalities, Open Space Preservation, and Urban Sprawl.” Regional Science and Urban Economics 34: 705-725.

Klaiber, H.A. and D.J. Phaneuf (2010). "Valuing Open Space in a Residential Sorting Model of the Twin Cities." Journal of Environmental Economics and Management 60: 57-77.

Kopits, E., V. McConnell, and M. Walls. 2007. "The Trade-off between Private Lots and Public Open Space in Subdivisions at the Urban-Rural Fringe.” American Journal of Agricultural Economics 89(5): 1191-1197.

Lewis, D.J., and A.J. Plantinga. 2007. "Policies for Habitat Fragmentation: Combining Econometrics with GIS-Based Landscape Simulations.” Land Economics 83(2): 109-127.

Lewis, D.J., B. Provencher, and V. Butsic. 2009. “The Dynamic Effects of Conserved open space Policies on Residential Development Density.” Journal of Environmental Economics and Management 57: 239-252.

Lewis, D.J. 2010. “An Economic Framework for Forecasting Land-Use and Ecosystem Change.” Resource and Energy Economics 32(2): 98-116.

Lohse, K. A., D. A. Newburn, J. J. Opperman, and A. M. Merenlender. 2008. "Forecasting Relative Impacts of Land Use on Anadromous Fish Habitat to Guide Conservation Planning.” Ecological Applications 18:467-482. 
McConnell, V. and M. Walls. 2005. "The Value of Open Space: Evidence from Studies of Nonmarket Benefits.” Resources for the Future.

Merryfield, N, E. Epstein, A. Galvin, E. Judziewicz, and W. Smith. 2000. “A Data Compilation and Assessment of Coastal Wetlands of Wisconsin's Great Lakes.” Natural Heritage Inventory Program Bureau of Endangered Resources. Wisconsin Department of Natural Resources. http://dnr.wi.gov/wetlands/cw/pdfs/Phase1_report.pdf.

Nelson, G.C., V. Harris, S.W. Stone. 2001. "Deforestation, Land Use, and Property Rights: Empirical Evidence from Darien, Panama.” Land Economics 77(2): 187-205.

Newburn, D.A., and P. Berck. 2006. "Modeling Suburban and Rural-Residential Development beyond the Urban Fringe." Land Economics 82(4): 481-499.

Papke, L.E. and J.M. Wooldridge. 2008. "Panel Data Methods for Fractional Response Variables with an Application to Test Pass Rates." Journal of Econometrics 148: 121-133.

Radeloff, V.C., Stewart, S.I., Hawbaker, T.J., Gimmi, R., Pidgeon, A.M., Flather, C.H., Hammer, R.B., and D.P. Helmers. 2010. "Housing Growth in and near United States Protected Areas Limits their Conservation Value." Proceedings of the National Academy of Sciences 107(2): 940-945.

Sander, H. A., and Polasky, S. 2009. "The value of views and open space: Estimates from a hedonic pricing model for Ramsey County, Minnesota, USA." Land Use Policy, 26(3), 837-845.

Timmins, C., and W. Schlenker. 2009. "Reduced-Form Versus Structural Modeling in Environmental and Resource Economics." Annual Review of Resource and Environmental Economics, 1: 351-380. 
Thorsnes, P. 2002. "The Value of a Suburban Forest Preserve: Estimates from Sales of Vacant Residential Building Lots.” Land Economics 78(3):426-441.

Towe, C.A., Nickerson, C.J., and N. Bockstael. 2008. “An Empirical Examination of the Timing of Land Conversions in the Presence of Farmland Preservation Programs." American Journal of Agricultural Economics 90(3): 613-626.

Tyrväinen, L., \& Miettinen, A. 2000. "Property prices and urban forest amenities." Journal of Environmental Economics and Management, 39(2), 205-223.

U.S. Census Bureau. 2012. "State and County QuickFacts: Door County, Wisconsin.” http://quickfacts.census.gov/qfd/states/55/55029.html

U.S. Census of Agriculture: Historical Census Publications. http://www.agcensus.usda.gov/Publications/Historical_Publications/index.php

Wallace, N. E. 1988. "The Market Effects of Zoning Undeveloped Land: Does Zoning Follow the Market?" Journal of Urban Economics 23:307-326.

Walsh, R. 2007. "Endogenous Open Space Amenities in a Locational Equilibrium." Journal of Urban Economics 61: 319-344.

Wooldridge, J.M. 2009. Introductory Econometrics: A Modern Approach, fourth edition. SouthWestern Cengage Press. Mason, Ohio.

Wooldridge, J.M. 2010. Econometric Analysis of Cross Section and Panel Data, second edition. The MIT Press. Cambridge, Massachusetts.

Wrenn, D.H. and E.G. Irwin. 2012. "How Do Land Use Policies Influence Fragmentation? An Econometric Model of Land Development with Spatial Simulation.” Environmental Economics 3(4): 82-96 
Wu, J. and A.J. Plantinga. 2003. "The Influence of Public Open Space on Urban Spatial Structure.” Journal of Environmental Economics and Management 46: 288-309. 


\section{Endnotes}

${ }^{\mathrm{i}}$ For example, early $20^{\text {th }}$ century U.S. National Forest purchases comprise the large majority of current National Forest stock and their conservation was originally set in the Weeks Act and motivated by ensuring a steady supply of timber. Modern federal conservation purchases are almost always driven by habitat protection or recreation rather than timber production. In contrast, modern NGOs like the Nature Conservancy will guide some purchases to areas that protect wildlife habitat for specific species. Others, like the Western Rivers Conservancy will purchase river corridors for watershed protection and public fishing access.

ii There are many ways to define open space and we recognize that open space may enter the utility function of nearby property owners in a complicated manner. We focus on the nearest parcel because this measure is easily understood and policy relevant at the local level.

iii Private developable open space may also provide distance-based amenities to residents due to a lack of nearby development (Irwin and Bockstael 2001, Irwin 2002). The extent to which omitting private developable open space from the analysis affects our results will be discussed in the identification strategy (Section 4.3).

iv The permitted uses on conservation easements vary by deed but generally the landowner can continue to use the land for agriculture, forestry, noncommercial recreation and limited residential use.

${ }^{\mathrm{v}}$ MFL lands are 25- or 50-year commitments to sustainable forest management. MFL-open lands are open to public foot traffic including hunting, fishing, hiking, sight-seeing. 
${ }^{\mathrm{vi}}$ Our GIS strategy for rectifying and digitizing historical parcel maps follows the approach outlined in Lewis et al. (2009).

${ }^{v i i}$ We have digitized historic zoning and plat maps for the following years: 1978, 1980, 1982, 1985, 1987, 1990, 1993, 1996, 2000, 2005, and 2009.

${ }^{\text {viii }}$ Although zoning classifications and land use appear to be highly correlated, there are two potential concerns with using zoning to identify the sample of agricultural and residential parcels - endogeneity and sample selection bias. Zoning policies may be endogenous to the landowner's subdivision decision if local planners use some of the same unobserved variables to set zoning policies as landowners use to decide whether to develop their land (Wallace 1988; Butsic et al. 2011). Sample selection bias arises if the sample is not representative of a larger population to which results are claimed to apply i.e. the sample of parcels that are zoned agricultural might not be representative of the parcels that are in agricultural use if the zoning process systematically zones certain parcels and not others. Neither of these concerns is an issue in our analysis. We use the binary agricultural/residential zoning classification to identify our sample, not as a righthand side variable, and our sample of agricultural parcels is a sample of parcels zoned agricultural, and out-of-sample inferences can be made with this equivalence in mind.

ix Agricultural zoning includes: "A-1", "A-2", "A-3", "A-4", "A-5", "A-6", "General Rural", "Prime Agricultural", "General Agricultural", "Exclusive Agricultural", "Heartland", "Heartland - 3.5", "Heartland - 5", "Heartland - 10", "Countryside", "Countryside 5", "Rural Community", and "Rural Residential". 
${ }^{x}$ Residential zoning includes: "R-1","R-2","R-3", "Single-Family Residential", "Single Family 20,000", "Single Family - 30,000", "High Density Residential", "Estate", "Small Estate Residential", and "Neighborhood Residential".

${ }^{x i}$ We cannot identify the development of agricultural parcels if parcels subdivide between 1978 and 2009 but are rezoned before 1978 or after 2009. This truncation problem is likely to be minor because agricultural parcels that do subdivide for development are rezoned on average 2.5 years before they subdivide and we observe parcels every 3 years. However, we do investigate this issue in more depth. We redefine the development of agricultural parcels to only include parcels that subdivided and rezoned within 7 years of each other and used only the data from 1985-1999. This sample does not have a truncation issue; we can identify rezoning and subdivision in the 7 years before 1985 and in the 7 years after 1999. The results are robust across the entire data set and the redefined data set, therefore, we proceed using the entire data set. The results are also robust when we define the development of agricultural parcels to only include parcels that subdivided and rezoned within 4 years (sample from 1982-2005).

${ }^{x i i}$ Wisconsin enacted a new comprehensive planning and smart growth law (1999 Wisconsin Act 9) in 1999 requiring that subdivision plat approvals comply with county and local comprehensive plans. This new legislation can partly explain the large increase in the rate of subdivision and density of development between 1996 and 1999. Since this was a statewide law that affected our entire study area but could differentially affect towns, we control for this pre-emptive subdivision with time fixed effects and municipality/time fixed effects in estimation. 
xiii We do explore an additional open space variable measuring the percentage of conserved openspace within a half-mile radius of each developable parcel in the Supplementary Appendix Section S.3.

${ }^{\text {xiv }}$ Although not the focus of our paper, recent literature has found evidence that minimum lot size zoning can be endogenous to landowners' subdivision decision if local planners consider the land market when making zoning decisions (Butsic et al. 2011). The identification strategy outlined in Section 3.5 can also be used to control for the endogeneity of zoning policies.

${ }^{\mathrm{xv}}$ We thank an anonymous reviewer for the suggestion to add a quadratic specification on minimum lot size zoning.

${ }^{x v i}$ Tourism is centered on the coast of Green Bay, which is more developed than the coast of Lake Michigan.

xvii We thank an anonymous reviewer for the suggestion to add a quadratic specification on private parcel size.

xviii It is quite common for the mean variables (the Mundlak devise) to be strongly correlated with the time-varying co-variates on which it is based. The correlation coefficient for the primary open-space variable is about 0.95 . Fortunately, we can still estimate marginal effects on distance to conserved open space that are significantly different from zero, indicating we have sufficient variation to overcome any multicollinearity. This variation comes from two sources. First, we have a large number of observations in both the agricultural $(\mathrm{N}=20,947)$ and residential $(\mathrm{N}=32,330)$ samples. Second, we have significant temporal variation in a parcel's distance to conserved open space, as the mean distance to open space decreased from 0.95 miles in 1978 to 
0.48 miles in 2005 . Thus, in the language of panel data estimators, we have a sufficient amount of within variation to facilitate a reasonably precise estimation even with our use of the Mundlak devise to approximate parcel fixed effects.

${ }^{\text {xix }}$ The municipalities in Door County range from a population of 313 people (Ephraim Village) to 8,800 people (City of Sturgeon Bay) and range from a size of 0.5 square miles (Village of Forestville) to 189.5 square miles (Town of Liberty Grove) (US Census 2008).

${ }^{x x}$ The $L(d)$ function measures the average number of neighbors at a given distance compared to the average concentration of points within the area as a measure of clustering (or dispersion).

$L(d)=\sqrt{\frac{A \sum_{i=1}^{N} \sum_{j \neq i}^{N} l(i, j)}{\pi N(N-1)}}$ where $A$ is area, $N$ is the number of points, $d$ is the distance, and $l=\left\{\begin{array}{l}1 \text { when the distance between } \mathrm{i} \text { and } \mathrm{j} \text { is less than or equal to } \mathrm{d} \\ 0 \text { otherwise }\end{array}\right.$ ${ }^{x x i}$ The final results are robust to excluding the three municipalities that rejected the null hypothesis of complete spatial randomness (the Towns of Sturgeon Bay, Sevastopol, and Gibraltar). We thank an anonymous reviewer for this comment.

xxii We thank an anonymous reviewer for this suggestion.

xxiii The subscript $a$ denotes division of the original coefficient by $\left(1+\sigma_{a}^{2}\right)^{1 / 2}$ which comes from a mixing property of the normal distribution (see Papke and Wooldridge 2008)

${ }^{\text {xxiv }}$ Other studies that have generated panel data of land use change using this approach include Lewis et al. (2009), Butsic et al. (2011), and Wrenn and Irwin (2012). 


\section{Figures}

Figure 1. Spatial Pattern of Development and Conserved open space (1978-2009)

Fig. la. Subdivision

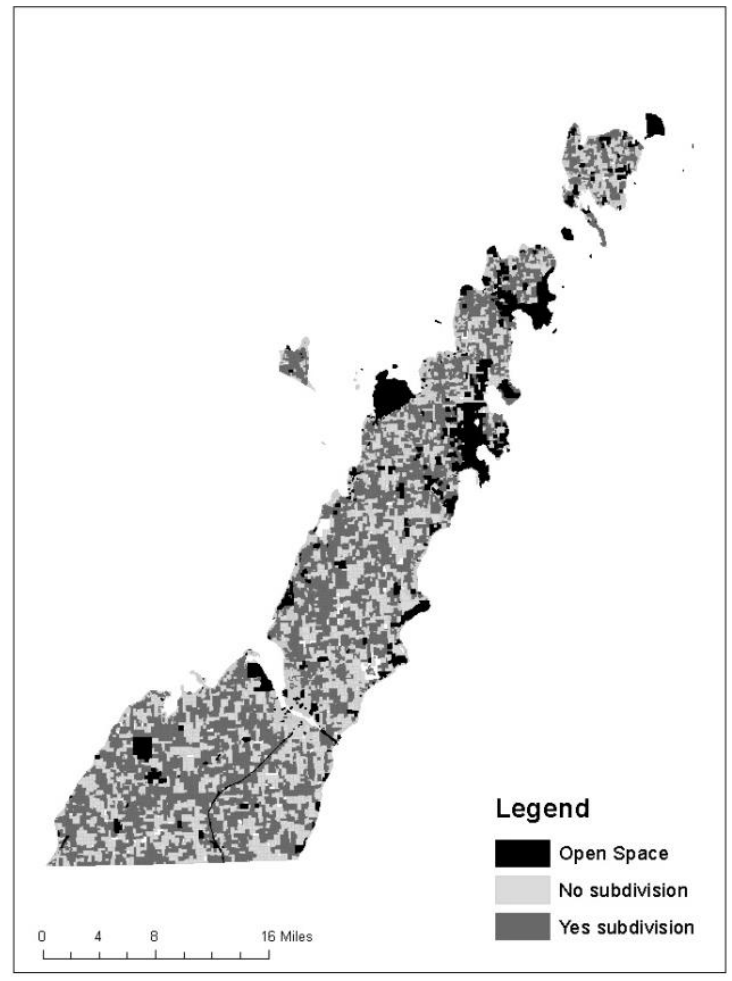

Fig. 1b. Conserved open space

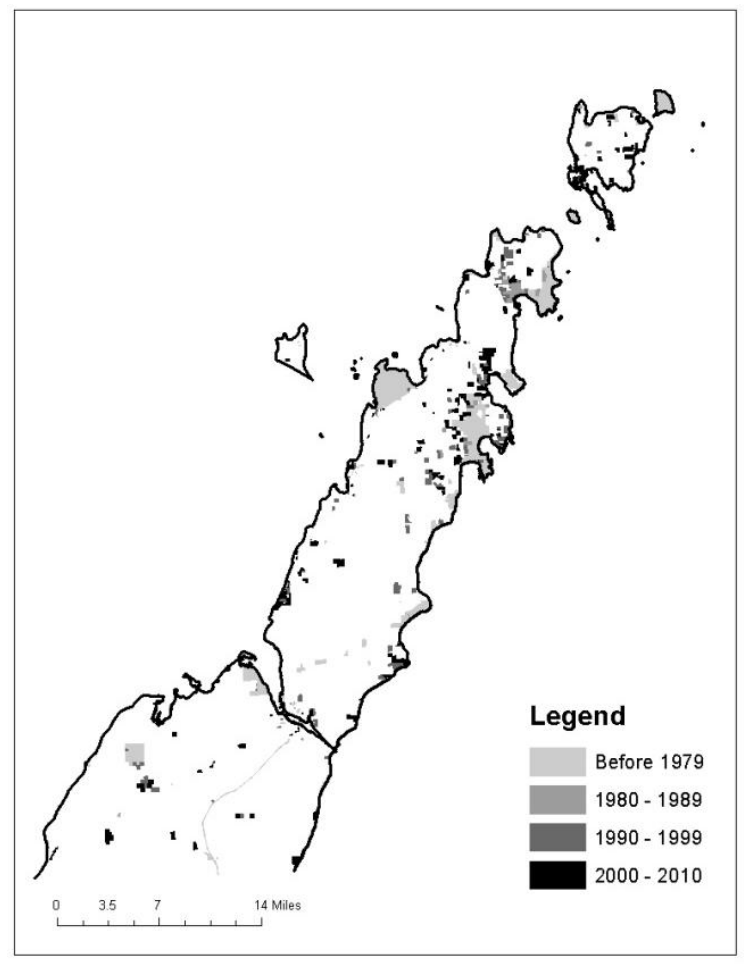


Figure 2. Landscape Simulation Results - Estimated Distribution of Net Change in Development from Creation of Individual Conserved Open Space in Door Co., WI (1978-2009)

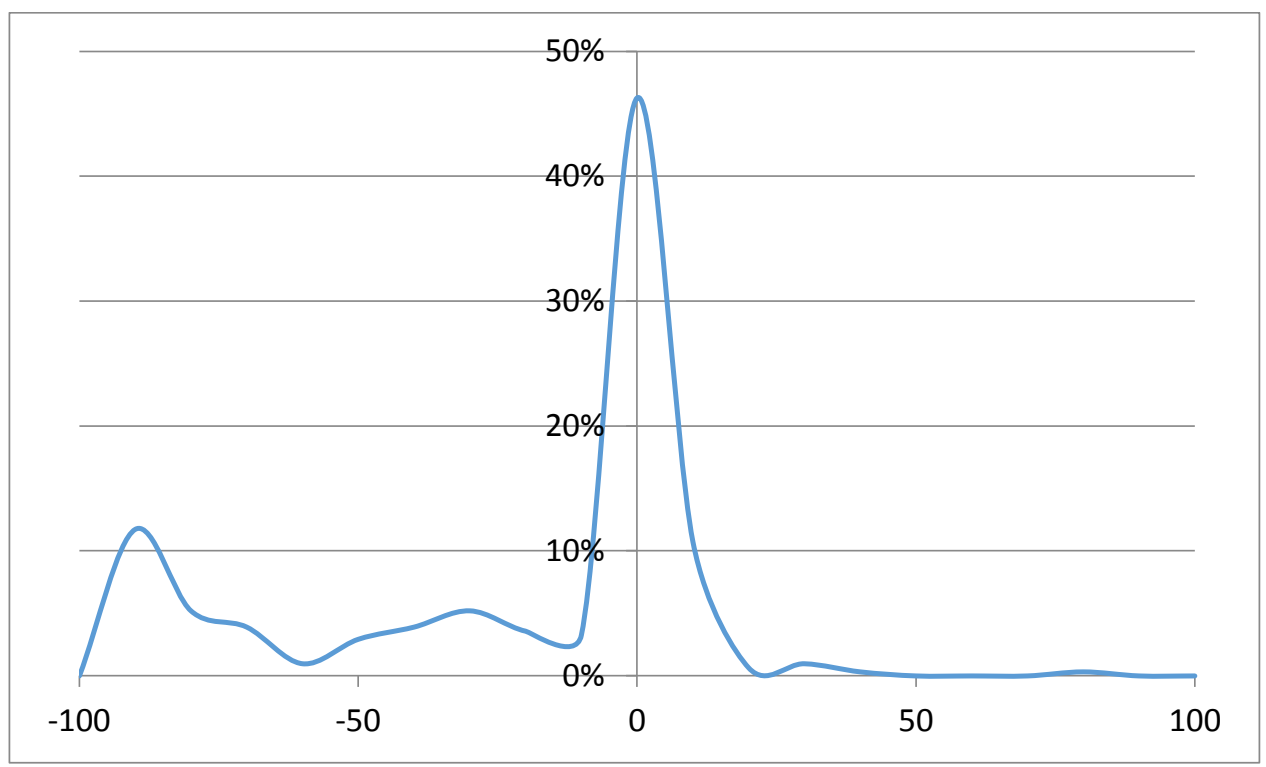

Percentage of conserved open spaces that lowered local development $=$ $79 \%$

Percentage of conserved open spaces that increased local development $=$ $21 \%$

Note: Negative values indicate that conserved open space lowers net development; positive values indicate that conserved open space increases net development. 
Tables

Table I: Summary of variables used in estimation

\begin{tabular}{|c|c|c|c|c|c|}
\hline Variable & Description & Mean & Std. Dev. & Min & Max \\
\hline \multicolumn{6}{|c|}{ Time-varying Characteristics } \\
\hline open_dist & Distance to open space (miles) & 0.80 & 0.70 & 0 & 4.96 \\
\hline open_size & Size of nearest open space (acres) & 414.13 & 1008.35 & 0.037 & 4864.28 \\
\hline open_big & $\begin{array}{l}=1 \text { for open space in the } 95^{\text {th }} \text { percentile of } \\
\text { size }\end{array}$ & & & & \\
\hline \multirow{3}{*}{ split } & $=0$ otherwise & 0.075 & 0.26 & 0 & 1 \\
\hline & $\begin{array}{l}=1 \text { if a parcel can legally only split into two } \\
\text { parcels }\end{array}$ & & & & \\
\hline & $=0$ otherwise & 0.23 & 0.42 & 0 & 1 \\
\hline minlot & Minimum lot size (zoning) (acres) & 2.51 & 5.54 & 0.230 & 35 \\
\hline \multicolumn{6}{|c|}{ Time-invariant Characteristics } \\
\hline area & Area of parcel (acres) & 24.69 & 44.41 & 0.46 & 871.03 \\
\hline shore_dist & $\min ($ distance to bay, distance to lake) (mile) & 1.08 & 1.38 & 0.0054 & 8.44 \\
\hline \multirow[t]{2}{*}{ bay_dummy } & $=1$ if parcel is closer to the bay & & & & \\
\hline & $=0$ if parcel is closer to the lake & 0.51 & 0.50 & 0 & 1 \\
\hline \multirow{2}{*}{$\begin{array}{l}\text { GB_dist } \\
\text { pbsmnt }\end{array}$} & Distance to City of Green Bay (mile) & 52.54 & 16.03 & 17.88 & 83.79 \\
\hline & $\begin{array}{l}\text { Proportion of parcel rated limited for } \\
\text { dwelling with basements }\end{array}$ & 0.62 & 0.37 & 0 & 1 \\
\hline pslope & Proportion of parcel with a slope of $15-25$ & 0.031 & 0.12 & 0 & 1 \\
\hline pflood & Proportion of parcel with frequent flooding & 0.048 & 0.14 & 0 & 1 \\
\hline
\end{tabular}


Table II: Rate of Subdivision (proportion of parcels subdivided since the previous plat observation, $0-1$ ) by year and land use

\begin{tabular}{|c|c|c|c|c|c|}
\hline year & $\begin{array}{c}<=0.5 \mathrm{mi} \text { to } \\
\text { nearest } \\
\text { conserved } \\
\text { open space }\end{array}$ & $\begin{array}{c}>0.5 \mathrm{mi} \text { to } \\
\text { nearest } \\
\text { conserved } \\
\text { open space } \\
\end{array}$ & average & $\begin{array}{c}\text { Number of } \\
\text { subdivisions } \\
\text { (average) }\end{array}$ & $\begin{array}{c}\text { Number of } \\
\text { subdividable } \\
\text { parcels } \\
\text { (average) } \\
\end{array}$ \\
\hline \multicolumn{6}{|c|}{ Agricultural } \\
\hline 1978 & 0.0270 & 0.0227 & 0.0244 & 72 & 2,948 \\
\hline 1980 & 0.0286 & 0.0165 & 0.0205 & 45 & 2,198 \\
\hline 1982 & 0.0245 & 0.0238 & 0.0245 & 60 & 2,445 \\
\hline 1985 & 0.0432 & 0.0381 & 0.0410 & 102 & 2,488 \\
\hline 1987 & 0.0308 & 0.0217 & 0.0247 & 66 & 2,676 \\
\hline 1990 & 0.0372 & 0.0241 & 0.0282 & 75 & 2,655 \\
\hline 1993 & 0.0349 & 0.0297 & 0.0324 & 74 & 2,284 \\
\hline 1996 & 0.213 & 0.119 & 0.1709 & 169 & 989 \\
\hline 1999 & 0.118 & 0.0728 & 0.0956 & 76 & 795 \\
\hline 2005 & 0.141 & 0.0727 & 0.1097 & 97 & 884 \\
\hline average & 0.0535 & 0.0341 & 0.0394 & 83.6 & $2,036.2$ \\
\hline \multicolumn{6}{|c|}{ Residential } \\
\hline 1978 & 0.0353 & 0.0386 & 0.0386 & 102 & 2,641 \\
\hline 1980 & 0.0238 & 0.0189 & 0.0212 & 57 & 2,684 \\
\hline 1982 & 0.0253 & 0.00942 & 0.0163 & 41 & 2,514 \\
\hline 1985 & 0.0283 & 0.0221 & 0.0256 & 78 & 3,052 \\
\hline 1987 & 0.0101 & 0.0163 & 0.0136 & 42 & 3,099 \\
\hline 1990 & 0.0216 & 0.0161 & 0.0195 & 67 & 3,437 \\
\hline 1993 & 0.0158 & 0.0151 & 0.0157 & 49 & 3,117 \\
\hline 1996 & 0.220 & 0.180 & 0.2567 & 663 & 2,583 \\
\hline 1999 & 0.0498 & 0.0446 & 0.0503 & 168 & 3,338 \\
\hline 2005 & 0.0510 & 0.0564 & 0.0554 & 189 & 3,409 \\
\hline average & 0.0538 & 0.0382 & 0.0465 & 145.6 & $2,987.4$ \\
\hline
\end{tabular}

Note: Subdivision in time $t$ is defined when it is recorded in the county plat maps or, more specifically, when we observe additional parcel centroids within a parcel in time $t+1$. 
Table III: Number of lots per acre created upon subdivision (since the previous plat observation) by year and land use

\begin{tabular}{|c|c|c|c|c|c|c|}
\hline year & $\begin{array}{c}<=0.5 \mathrm{mi} \text { to } \\
\text { nearest } \\
\text { conserved } \\
\text { open space }\end{array}$ & $\begin{array}{l}\text { Agricultural } \\
>0.5 \mathrm{mi} \text { to } \\
\text { nearest } \\
\text { conserved } \\
\text { open space }\end{array}$ & average & $\begin{array}{c}<=0.5 \mathrm{mi} \\
\text { to nearest } \\
\text { conserved } \\
\text { open } \\
\text { space } \\
\end{array}$ & $\begin{array}{c}\text { Residential } \\
>0.5 \mathrm{mi} \text { to } \\
\text { nearest } \\
\text { conserved } \\
\text { open } \\
\text { space } \\
\end{array}$ & average \\
\hline 1978 & 0.119 & 0.0985 & 0.104 & 0.286 & 0.107 & 0.179 \\
\hline 1980 & 0.0604 & 0.0993 & 0.0829 & 0.155 & 0.101 & 0.124 \\
\hline 1982 & 0.0470 & 0.0678 & 0.0626 & 0.201 & 0.0892 & 0.163 \\
\hline 1985 & 0.0576 & 0.0884 & 0.0800 & 0.275 & 0.152 & 0.215 \\
\hline 1987 & 0.0396 & 0.0862 & 0.0707 & 0.227 & 0.140 & 0.171 \\
\hline 1990 & 0.0568 & 0.118 & 0.0965 & 0.224 & 0.126 & 0.186 \\
\hline 1993 & 0.0936 & 0.0647 & 0.0752 & 0.177 & 0.166 & 0.173 \\
\hline 1996 & 0.361 & 0.296 & 0.323 & 0.553 & 0.522 & 0.542 \\
\hline 1999 & 0.113 & 0.154 & 0.136 & 0.563 & 0.389 & 0.503 \\
\hline 2005 & 0.139 & 0.110 & 0.126 & 0.763 & 0.295 & 0.622 \\
\hline average & 0.150 & 0.135 & 0.141 & 0.507 & 0.330 & 0.439 \\
\hline
\end{tabular}

Note: the average size of agricultural parcels that subdivide is 51.31 acres and the average size of residential parcels that subdivide is 22.07 acres. There were a total of 8568 new lots created between 1978 and 2009. 
Table IV: Additional open spaces by size and year

\begin{tabular}{|c|c|c|c|c|c|c|}
\hline & 0-1 acres & $1-10$ acres & $10-100$ acres & $100-1000$ acres & $>1000$ acres & total \\
\hline Before 1978 & 38 & 53 & 24 & 12 & 5 & 132 \\
\hline 1978 & 2 & 6 & 1 & 0 & 0 & 9 \\
\hline 1980 & 3 & 0 & 2 & 1 & 0 & 6 \\
\hline 1982 & 0 & 1 & 1 & 2 & 2 & 6 \\
\hline 1985 & 2 & 4 & 0 & 1 & 1 & 8 \\
\hline 1987 & 1 & 4 & 0 & 3 & 0 & 8 \\
\hline 1990 & 4 & 2 & 3 & 1 & 1 & 11 \\
\hline 1993 & 0 & 6 & 1 & 4 & 2 & 13 \\
\hline 1996 & 4 & 6 & 6 & 8 & 1 & 25 \\
\hline 1999 & 7 & 11 & 10 & 2 & 2 & 32 \\
\hline 2005 & 15 & 21 & 24 & 17 & 3 & 80 \\
\hline
\end{tabular}


Table V: Average partial effect on the probability of subdivision of a quarter-mile decrease in the distance to open space (percentage points)

\begin{tabular}{|c|c|c|c|c|c|}
\hline Model & Model 1 & Model 2 & Model 3 & Model 4 & Model 5 \\
\hline \multicolumn{6}{|c|}{ Agricultural } \\
\hline $\begin{array}{l}\text { Average effect } \\
\text { (all parcels) }\end{array}$ & $\begin{array}{l}0.252 * * \\
(0.0853)\end{array}$ & $\begin{array}{c}0.140+ \\
(0.0826)\end{array}$ & $\begin{array}{c}0.319 \\
(0.224)\end{array}$ & $\begin{array}{c}0.221 \\
(0.210)\end{array}$ & $\begin{array}{c}0.242 \\
(0.208)\end{array}$ \\
\hline $\begin{array}{c}\text { Average effect } \\
\text { (parcels within } 0.5 \\
\text { miles of open space) }\end{array}$ & $\begin{array}{c}0.873 * * \\
(0.337)\end{array}$ & $\begin{array}{l}0.727 * \\
(0.315)\end{array}$ & $\begin{array}{l}0.964 * \\
(0.431)\end{array}$ & $\begin{array}{l}0.895 * \\
(0.412)\end{array}$ & $\begin{array}{l}0.889 * \\
(0.404)\end{array}$ \\
\hline \multicolumn{6}{|c|}{ Residential } \\
\hline $\begin{array}{l}\text { Average effect } \\
\text { (all parcels) }\end{array}$ & $\begin{array}{c}0.595 * * \\
(0.115)\end{array}$ & $\begin{array}{c}0.454 * * \\
(0.119)\end{array}$ & $\begin{array}{c}0.719 * * \\
(0.205)\end{array}$ & $\begin{array}{c}0.696^{* *} \\
(0.207)\end{array}$ & $\begin{array}{l}0.526^{*} \\
(0.215)\end{array}$ \\
\hline $\begin{array}{c}\text { Average effect } \\
\text { (parcels within } 0.5 \\
\text { miles of open space) }\end{array}$ & $\begin{array}{l}1.09 * * \\
(0.235)\end{array}$ & $\begin{array}{c}0.920 * * \\
(0.238)\end{array}$ & $\begin{array}{l}1.31 * * \\
(0.309)\end{array}$ & $\begin{array}{l}1.27 * * \\
(0.312)\end{array}$ & $\begin{array}{l}1.07 * * \\
(0.318)\end{array}$ \\
\hline Time Dummies & Yes & Yes & Yes & Yes & Yes \\
\hline Municipality Dummies & No & No & No & Yes & No \\
\hline $\begin{array}{l}\text { Municipality Dummies } \\
\text { *Time Dummies }\end{array}$ & No & Yes & No & No & Yes \\
\hline Correlated Random Effects & No & No & Yes & Yes & Yes \\
\hline
\end{tabular}

Note: Standard errors in parentheses. The average effects are presented in terms of a change in percentage points on a $0-100$ scale. $+\mathrm{p}<0.10,{ }^{*} \mathrm{p}<0.05, * * \mathrm{p}<0.01$ 
Table VI: Average partial effect of a quarter-mile decrease in the distance to open space on the number of lots per acre (percentage change)

\begin{tabular}{|c|c|c|c|c|c|}
\hline Model & Model 1 & Model 2 & Model 3 & Model 4 & Model 5 \\
\hline \multicolumn{6}{|c|}{ Agricultural } \\
\hline Average effect & -0.279 & $-7.81 * *$ & -1.45 & $-6.18 *$ & $-7.64 * *$ \\
\hline & $(2.24)$ & $(2.21)$ & $(1.93)$ & $(1.17)$ & $(2.18)$ \\
\hline $\begin{array}{c}\text { Average effect } \\
\text { (parcels within } 0.5 \\
\text { miles of open space) }\end{array}$ & $\begin{array}{l}-0.260 \\
(6.80)\end{array}$ & $\begin{array}{c}-18.02 * * \\
(6.04)\end{array}$ & $\begin{array}{l}-2.23 \\
(6.14)\end{array}$ & $\begin{array}{c}-14.14^{*} \\
(6.18)\end{array}$ & $\begin{array}{c}-17.10 * * \\
(6.02)\end{array}$ \\
\hline \multicolumn{6}{|c|}{ Residential } \\
\hline Average effect & $15.00 * *$ & $5.64 *$ & $9.50 * *$ & $5.05 *$ & 1.98 \\
\hline & $(2.62)$ & $(2.52)$ & $(1.95)$ & $(2.01)$ & $(2.03)$ \\
\hline $\begin{array}{c}\text { Average effect } \\
\text { (parcels within } 0.5 \\
\text { miles of open space) }\end{array}$ & $\begin{array}{c}24.30 * * \\
(5.34)\end{array}$ & $\begin{array}{l}10.94 * \\
(4.94)\end{array}$ & $\begin{array}{c}16.28 * * \\
(4.01)\end{array}$ & $\begin{array}{l}7.53+ \\
(4.01)\end{array}$ & $\begin{array}{l}3.78 \\
(3.96)\end{array}$ \\
\hline Time Dummies & Yes & Yes & Yes & Yes & Yes \\
\hline Municipality Dummies & No & No & No & Yes & No \\
\hline $\begin{array}{l}\text { Municipality Dummies } \\
\text { *Time Dummies }\end{array}$ & No & Yes & No & No & Yes \\
\hline $\begin{array}{l}\text { Correlated Random Effects } \\
\text { in the selection model }\end{array}$ & No & No & Yes & Yes & Yes \\
\hline
\end{tabular}

Note: Standard errors in parentheses. The average effects are presented in terms of a percentage change in the number of new lots per acre on a $0-100$ scale. $+\mathrm{p}<0.10,{ }^{*} \mathrm{p}<0.05, * * \mathrm{p}<0.01$ 
Table VII: Summary of variables used in post-estimation analysis of simulation results

\begin{tabular}{ccccc}
\hline Variables & Mean & Std. Dev. & Min & Max \\
\hline proportion change in new & -0.176 & 0.304 & -0.989 & 0.9274 \\
parcels & 177.112 & 568.710 & 0.0367 & 4140.536 \\
open space size (acres) & 0.234 & 0.340 & 0 & 2.352 \\
$\begin{array}{c}\text { substitutability } \\
\text { proportion of agricultural } \\
\text { parcels }\end{array}$ & 0.225 & 0.366 & 0 & 1 \\
\hline
\end{tabular}


Table VIII: Post-estimation regression results

\begin{tabular}{|c|c|c|c|c|}
\hline Variables & Coef. & Std. Err. & $\mathbf{t}$ & $\mathbf{P}>\mathbf{t}$ \\
\hline \multicolumn{5}{|c|}{ Dependent variable $(y)=$ proportion change in new parcels } \\
\hline open space size (acres) & 0.0000751 & 0.0000375 & 2.00 & 0.047 \\
\hline $\begin{array}{c}\text { substitutability } \\
(y \leq 0) \\
\text { substitutahility }\end{array}$ & -0.517 & 0.161 & -3.21 & 0.002 \\
\hline$(y>0)$ & 3.016 & 0.494 & 6.10 & 0.000 \\
\hline $\begin{array}{c}\text { proportion of agricultural } \\
\text { parcels }\end{array}$ & -0.152 & 0.0947 & -1.60 & 0.111 \\
\hline constant & -0.377 & 0.0582 & -6.48 & 0.000 \\
\hline
\end{tabular}

Note: Municipality dummies not reported. 